\title{
COMUNICAÇÃO ESTRATÉGICA: PÚBLICOS DE INTERESSE E PERSONA
}

\author{
ORGANIZACIONAL
}

\author{
Adriana Sturmer ${ }^{1}$ \\ Cristiano Max Pereira Pinheiro² \\ Luana Leão ${ }^{3}$ \\ Mikaela de Souza ${ }^{4}$ \\ Recebido em: 27 set. 2018 \\ Aceito em: 18 fev. 2019
}

\begin{abstract}
Como citar este artigo: STURMER, Adriana et al. COMUNICAÇÃO ESTRATÉGICA: PÚBLICOS DE INTERESSE E PERSONA ORGANIZACIONAL. Revista Visão: Gestão Organizacional, Caçador, SC, Brasil, p. 25-43, jun. 2019. ISSN 2238-9636. Disponível em:

<http://dx.doi.org/10.33362/visao.v8i1.1728>.
\end{abstract}

Resumo: O presente trabalho tem o objetivo de discutir o conceito de personas junto às demais abordagens sobre públicos de interesse no contexto da comunicação estratégica organizacional. Do ponto de vista de seu objetivo, o artigo constitui uma pesquisa exploratória de abordagem qualitativa. A pesquisa bibliográfica e a pesquisa documental são os procedimentos técnicos utilizados para resgatar as classificações de públicos de interesse mais tradicionais, apresentar o conceito de personas e discutir as noções de Inbound Marketing e Inbound $P R$. A intenção é contribuir para estabelecer um debate, baseado na noção de personas, sobre formatos, modelos ou caminhos mais específicos para identificar as características dos públicos com os quais uma organização se relaciona, atrelando tais características à estratégia de comunicação. Como resultados, cita-se que é possível identificar, através da metodologia Inbound $P R$, o potencial de influência das relações públicas na construção de uma comunicação de resultados que seja voltada para o indivíduo, para as personas.

Palavras-Chave: Relações públicas. Personas. Públicos de interesse.

STRATEGIC COMMUNICATION: PUBLIC INTEREST AND ORGANIZATIONAL PERSONA

Abstract: The present work has the objective of discussing the concept of personas along with the other approaches on public interest in the context of strategic organizational communication. From the point of view of its objective, the article constitutes an exploratory research of qualitative approach. Bibliographical research and documentary

\footnotetext{
${ }^{1}$ Doutora em Comunicação pela Universidade Federal de Santa Maria (UFSM/2018); Professora e coordenadora dos cursos de Relações Públicas e Jornalismo na Universidade Feevale.

2 Doutor em Comunicação Social pela PUCRS; Coordenador do Laboratório de Criatividade e Professor do Mestrado em Indústria Criativa (Universidade Feevale).

${ }^{3}$ Graduada em Relações Públicas pela Universidade Feevale.

${ }^{4}$ Graduada em Design Gráfico pela Universidade Feevale; Bolsista do Laboratório de Criatividade da Universidade Feevale. E-mail: mikaela@feevale.br.
} 
research are the technical procedures used to retrieve the most traditional classifications of interest, present the concept of personas and discuss the notions of Inbound Marketing and Inbound PR. The intention is to contribute to establish a debate, based on the notion of personas, about more specific formats, models or paths to identify the characteristics of the public with which an organization relates, linking such characteristics to the communication strategy. As results, it is possible to identify, through the Inbound PR methodology, the potential influence of the public relations in the construction of a communication of results that is directed towards the individual, for the people.

Keywords: Public relations. Personas. Public interest.

\section{INTRODUÇÃO}

Comunicar de forma direcionada e eficaz é princípio primordial no desenvolvimento da comunicação estratégica de resultados, especialmente no contexto atual, no qual o indivíduo ganha ainda mais espaço e representatividade junto às organizações. Dessa forma, entender os interesses dos públicos que interferem na atividade organizacional para alcançar objetivos, tanto os sociais como os de negócios, se tornou questão de sobrevivência para uma empresa, já que o sucesso no alcance dos objetivos corporativos está ligado ao conhecimento, aproximação e relacionamento estabelecidos entre as organizações e seus públicos de interesse.

Umas das estratégias para tornar o processo de mapeamento de públicos eficaz e prático está, segundo se propõe aqui, na abordagem de personas, que tem potencial de aplicação sob a ótica das relações públicas. Sob a abordagem de personas, é possível lançar um olhar revitalizado a respeito de públicos de interesse: sem desconsiderar conceituações tradicionais de públicos em relações públicas, sugere-se a possibilidade de partir de abordagens mais atuais e com base em novas ferramentas e metodologias contemporâneas para as organizações.

Dessa forma, as classificações de público propostas em relações públicas, juntamente com a noção de personas na perspectiva da tecnologia (focada no usuário) e do ponto de vista do marketing (focado no cliente), podem tornar mais prático o mapeamento de públicos, levando em conta suas expectativas e necessidades, para que as organizações possam de fato entender os objetivos dos indivíduos que formam o público e definir com eficácia e agilidade os canais e meios de comunicação que devem ser utilizados na construção de relacionamento.

A revisão bibliográfica é base para o desenvolvimento da presente pesquisa, que se propõe a retomar as mais tradicionais classificações de públicos em relações públicas e discutir o conceito de personas junto a essas abordagens, no contexto da comunicação estratégica organizacional. 


\section{PROCEDIMENTOS METODOLÓGICOS}

Do ponto de vista de seus objetivos, o artigo constitui uma pesquisa exploratória de abordagem qualitativa. A pesquisa bibliográfica e a pesquisa documental são os procedimentos técnicos utilizados. Livros, e-books, artigos digitais e artigos científicos, alguns disponíveis na internet, são reconhecidos como formatos de pesquisa bibliográfica e foram aqui manuseados. O principal objetivo desse tipo de procedimento é "colocar o pesquisador em contato direto com tudo o que foi escrito, dito ou filmado sobre determinado assunto" (LAKATOS; MARCONI, 1995, p. 183).

Sendo assim, sobre as conceituações de públicos de interesse em relações públicas, destacam-se as obras de Simões (1995), Grunig (1984) e França (2011); e Cooper (2004) embasa o estudo das origens do conceito de personas e sua aplicação no segmento tecnológico, espaço em que foi criado e aplicado pela primeira vez. O template para a construção de personas foi desenvolvido pelo Hubspot (2017).

\section{COMUNICAÇÃO ESTRATÉGIA E PÚBLICO DE INTERESSE}

Os esforços de comunicação, quando voltados aos públicos de interesse e alinhados aos objetivos de negócio da organização, podem entregar resultados que transpõem a construção de presença e influência junto aos públicos que interferem em sua atuação, gerando, também, vantagem competitiva em comparação à concorrência.

Grunig (2011) contribui para a melhor compreensão da conexão entre a construção de relacionamento com públicos de interesse e o alcance de objetivos de negócio ao abordar dois ambientes distintos que fazem parte do contexto em que uma organização exerce suas atividades: o ambiente econômico e o ambiente sociopolítico, ou institucional.

O autor explora a segmentação desses dois ambientes ao expor a diferença existente entre os públicos contidos em cada um. Consumidores, concorrentes e fornecedores fazem parte do ambiente econômico de uma empresa e são eles que fornecem sustentação econômica para a atividade organizacional primária, já que "abastecem a organização com os recursos necessários e adquirem ou utilizam os produtos e serviços por ela fornecidos" (GRUNIG, 2011, p. 78).

Já o ambiente sociopolítico, também chamado de institucional, é composto por públicos que participam da consolidação da missão ou propósito da organização. São eles o governo, a comunidade, acionistas, funcionários, entidades de classe e grupos ativistas. Ao diferenciar o ambiente econômico do ambiente institucional, Wheelen e Hunger (apud GRUNIG, 2011) ressaltam que a organização atua no interior do ambiente econômico, que envolve sua atuação e esforços mercadológicos, porém tal atuação é influenciada pelo ambiente sociopolítico/institucional, que interfere diretamente na atuação corporativa. 
Pode não haver, entretanto, tanta clareza e lógica ao falar-se em públicos de interesse de uma organização. Identificar os designados "públicos" exige um estudo detalhado sobre os cenários de atuação da empresa, mapeamento de seus objetivos sociais e mercadológicos e compreensão a respeito dos grupos que interferem ou influenciam a atuação organizacional e suas respectivas expectativas - que, neste caso, não estão necessariamente relacionadas ao aspecto mercadológico da organização.

Desta forma, fica claro o papel da construção de relacionamento com públicos de interesse para a gestão estratégica e eficácia organizacional, já que, de acordo com o nível e efetividade do relacionamento estabelecido, os públicos podem apoiar e impulsionar uma empresa no alcance de sua missão, assim como podem também desviá-la de seu caminho devido à má gestão do relacionamento. Sendo assim, o conhecimento a respeito do público suas crenças, atitudes, preocupações e estilos de vida - possibilita ao comunicador "particularizar as mensagens, responder a uma necessidade percebida e oferecer argumentação de ação lógica" (FRANÇA, 2012, p. 8).

O mapeamento e compreensão das relações de poder envolvidas no âmbito dos públicos que não designam apenas o cliente ou consumidor, configura-se como um procedimento repleto de incertezas para a maior parte das organizações. Dessa forma, cabe apresentar algumas abordagens e classificações de públicos construídas ao longo do desenvolvimento da atividade profissional e acadêmica de relações públicas no Brasil e no mundo, apresentadas a seguir em quatro categorias.

\section{CLASSIFICAÇÃO BASEADA NA ESSENCIALIDADE E INTERDEPENDÊNCIA}

É evidente a forma como os relacionamentos corporativos fazem parte da sobrevivência de uma organização, e que qualquer instituição conta com uma rede de públicos que influenciam sua atividade. Essa influência é denominada por França (2011) de interdependência corporativa, em que os aspectos administrativos, jurídicos, sociais e ligados aos objetivos de negócio de uma organização interagem e estabelecem relação com diferentes grupos de indivíduos, os públicos de interesse.

Para estipular os fatores mais importantes e que conferem significado na relação entre organização e público, França (2012) estabelece a conceituação lógica de públicos. De acordo com o autor, o uso da lógica na classificação de públicos confere o raciocínio e a possibilidade de julgar corretamente e conhecer, de fato, o público. Para o autor, o uso da lógica no entendimento da relação entre empresa e público serve para determinar que os critérios de proximidade não são suficientes para classificar e segmentar um público, e que é necessário construir uma relação coerente na qual seja possível compreender o papel de cada público que interfere na atuação organizacional.

Para França (2012), a interdependência entre organização-públicos é estabelecida 
através de uma "codificação", ou categorização, lógica, que é, por sua vez, dividida por uma ideia de essencialidade. O autor acredita na aplicabilidade lógica do mapeamento de públicos em todos os tipos de relacionamento da organização, pois ele oferece aspectos fundamentais no estudo de públicos, tais como: o que move o público, o tipo de objetivo da relação, o nível de dependência entre as partes, "a temporalidade e a prioridade da relação" (FRANÇA, 2012, p. 76). Pela conceituação lógica, os públicos podem ser classificados em três categorias: essenciais (dos quais a organização depende para existir), não essenciais (que estabelecem relações de interesse nas atividades da organização) e de interferência (grupos externos à organização, que interferem no cenário no qual ela atua e que apresentam participação representativa perante a opinião pública e o mercado).

Embora a classificação lógica de públicos de interesse proposta por França leve em consideração os níveis de envolvimento de cada público com a organização e confira certa ordem na avaliação dos públicos, nem sempre ela é considerada prática pelas organizações, quando da estruturação de estratégias de relacionamento que gerem resultados de negócio. Tal fator, especificamente, parece ser o que inibe sua aplicação por algumas empresas, apesar do seu grande valor acadêmico.

\section{CLASSIFICAÇÕES BASEADAS EM CRITÉRIOS DEMOGRÁFICOS OU GEOGRÁFICOS}

A segmentação demográfica ou geográfica também é bastante utilizada para determinar públicos. Muitos profissionais acreditam que, ao dividir grupos de pessoas de acordo com idade, sexo, etnia, local de residência, já é possível obter informações que unificam públicos de acordo com suas características em comum. Para Grunig (1984), essa é uma forma ineficaz de mapear públicos, pois, dentro dessas características demográficas, podem tanto existir diversos públicos, como não existir público algum.

Nesses casos, de acordo com o autor, é comum profissionais que utilizam destas métricas, quando pressionados sobre uma definição precisa destes públicos, alegarem que se referem ao "público em geral". Grunig e Hunt (1984) afirmam no entanto, que o "público em geral" é uma impossibilidade lógica porque "públicos são sempre específicos; eles possuem sempre um problema em comum. Portanto, não podem ser gerais" (GRUNIG; HUNT, 1984, p. 138).

É comum que os públicos organizacionais sejam relacionados, também, de acordo com suas áreas de convivência. A definição de públicos mais aceita pelas escolas brasileiras, segundo França (2012, p. 34) defende a "classificação simplista", nas palavras do autor, de públicos internos, externos e mistos. WAY, Hebe (apud FORTES, 2002, p. 64), sob esta visão, classifica funcionários e seus respectivos familiares como "público interno" de uma organização. Já o "público externo" é dividido por critérios comerciais (cliente e consumidor), financeiros (bancos e agentes de crédito), governamentais (poderes Executivo, Legislativo e 
Judiciário, além de órgãos federais), comunitários (grupos organizados de ação ou pressão), docentes (na área educacional), comunicação (imprensa) e trabalhistas (sindicatos e entidades de classe).

França realizou um levantamento bastante aprofundado, que se resgata brevemente aqui, a respeito da abordagem dos públicos por critérios de proximidade. É de conhecimento comum no meio acadêmico de que o público interno de uma organização seja formado, basicamente, por funcionários. Para Ferreira (2001, apud FRANÇA, 2012, p. 36), o público interno é um "segmento de público constituído essencialmente dos diretores e empregados de uma empresa ou organização, incluindo, eventualmente, acionistas, conselheiros, vendedores". Lammertyn (1997 apud FRANÇA, 2012, p. 37) busca definir de forma mais específica a categoria de públicos internos, subdividindo-as em três níveis: gerencial (diretores, gerentes e subgerentes); dirigentes intermediários (chefes, subchefes e supervisão) e setor operacional (funcionários).

Quanto à definição de público externo, Ferreira (2001 apud FRANÇA, 2012, p. 38) afirma que o público externo é "o segmento de público de certa forma relacionado às atividades de uma empresa ou organização, mas não faz parte integrante desta". Exemplos de público externo são fornecedores, consumidores, autoridades governamentais e o "público em geral". Lammertyn (1997 apud FRANÇA, 2012, p. 39), por sua vez, caracteriza públicos externos de forma ampla, definindo-os como "os que influenciam na organização a partir de um interesse relativo". Dentro desta categoria, para o autor, cabem as mais variadas categorias de públicos da sociedade, desde consumidores e líderes de opinião, até bombeiros, polícia, jornalistas e partidos políticos.

Ainda na classificação geográfica de públicos, Lammertyn (1997 apud FRANÇA, 2012, p. 40) afirma que os públicos mistos "não estão estreitamente vinculados aos objetivos da organização, mas têm relação próxima com sua missão específica ainda que não pertençam a seus quadros de colaboradores permanentes". Exemplos de públicos mistos segundo a visão tradicional citada por França (2012) são: familiares dos empregados, fornecedores, acionistas e "até concessionários ou revendedores de produtos" (FRANÇA, 2012, p. 40).

A classificação de públicos como interno, externo e misto, no entanto, não parece ser específica e nem evidencia as necessidades ou interesses dos públicos junto à organização. Esse critério, além disso, simplifica a participação ou envolvimento de cada público, sem demonstrar os níveis de complexidade do relacionamento organizacional com cada um. Fortes (2003) enxerga como imprecisa a classificação geográfica, ou por área de convivência, uma vez que, para o autor, ela assemelha-se à definição de grupos, em que o público é identificado de forma ampla, sem foco em suas semelhanças e problemas.

Dentro da divisão de públicos por área de convivência, no entanto, é possível compreender que alguns ganham maior importância do que outros, conforme a ocasião. Neste 
caso, o critério de proximidade na classificação de públicos ganha relevância, pois "começa com o público interno, constituído por aqueles grupos humanos que têm contato mais próximo com a entidade e movimenta-se, de dentro para fora, através de círculos, quando a intimidade com a organização vai diminuindo gradativamente" (PENTEADO, 1984, p. 149). Embora também Penteado (1984) acredite que o critério de proximidade traga ordem à classificação de públicos em relações públicas, ele não transforma em método o trabalho de mapeamento e classificação de públicos e nem demonstra quais são as necessidades de cada público.

Segundo Fortes (2002), apesar de a ideia de Penteado trazer uma certa tranquilidade prática, ela "não resolve a preocupação de encontrar parâmetros de constância de um ajustamento sistemático ou requisitos únicos para metodizar a classificação de públicos" além de que, para o autor, a necessidade de cada público precisa ser trabalhada como um princípio e prática de relações públicas.

\section{CLASSIFICAÇÕES BASEADAS NO PODER EXERCIDO PELOS PÚBLICOS}

Para Simões (1995), o critério geográfico de classificação de públicos é de utilidade restrita, insuficiente para ilustrar a relação "público-organização" e serve somente para "enquadrar os distanciamentos dos públicos quanto ao centro de poder da organização" (SIMÕES, 1995, p. 131). De acordo com o autor, é mais coerente que os públicos sejam classificados quanto ao tipo de poder que exercem.

Com esse pensamento, o autor definiu, sob a tipologia de Lucien Matrat ${ }^{5}$, quatro tipos de óticas sobre públicos de interesse com base no poder que possuem. São eles: decisão, consulta, comportamento e opinião. O poder de decisão abrange os públicos dos quais a organização depende para exercer suas atividades, como o governo, que concede a existência da organização através do seu poder sobre a legislação. Ao poder de consulta estão relacionados os públicos que "são sondados pela organização, quando a mesma pretende agir. Os acionistas, por vezes, estão aí compreendidos" (SIMÕES, 1995, p. 132).

O poder de comportamento abrange os públicos que podem prejudicar ou favorecer a atividade da organização. Um exemplo de público que carrega tal poder comportamental são os funcionários, já que "as atividades fim e meio dependem deles" (SIMÕES, 1995, p. 132). O autor cita, também, os clientes como pertencentes a este público, já que são eles que condicionam a presença da organização no mercado através do consumo de seus produtos ou serviços.

Simões fala também sobre o poder de opinião dos públicos. O autor acrescenta a influência que certos públicos exercem sobre a opinião pública "[...] pela simples manifestação

\footnotetext{
${ }^{5}$ Lucien Matrat (1906-1998) é considerado o "pai" das relações públicas na França. É autor do Código de Atenas, aprovado, em 1965, pela Associação Internacional de Relações Públicas (IPRA), no qual estabelece as normas universais de conduta ética da profissão. Mais em https://www.ipra.org/history/ipras-story/
} 
de seu julgamento e seu ponto de vista" (SIMÕES, 1995, p. 132). Líderes de opinião são catalogados nessa tipologia, que pode ser exemplificada pela mídia, líderes comunitários, colunistas de jornais e formadores de opinião. No meio digital, cresce a presença de influenciadores e produtores de conteúdo digital, que podem ser caracterizados como os formadores de opinião da contemporaneidade, com grande prestígio junto ao público jovem.

Simões acredita que todas as classificações de públicos de interesses, contam com um elemento em comum: a pessoa, o indivíduo. Em relações públicas, a propósito, o autor é o primeiro a citar o conceito de personas, mesmo que, talvez, sem a intenção de problematizálo especificamente. Diz ele:

Os grupos têm por base a pessoa que, segundo definições da psicologia social, é uma unidade composta de uma única personalidade e de várias personagens. Significa sempre o indivíduo na sociedade, em face dos vários papéis que deve desempenhar (SIMÕES, 1995, p. 62).

Para o autor, cada indivíduo conta com uma personalidade, que é formada por: 1) a herança biológica; 2) a herança cultural (valores, crenças, normas e métodos); 3) as vivências, ou seja, todas as experiências vivenciadas e 4) a maturação (o desenvolvimento físico, intelectual e emocional). Durante a sua vida, entretanto, o indivíduo, que carrega a sua personalidade, exerce diferentes papéis perante a sociedade, os quais são chamados de personagens:

As personagens são caracterizadas pelo conjunto de papéis que a personalidade deve desempenhar em sua vida na sociedade. Quando se nasce recebem-se alguns já atribuídos pela sociedade. Durante a vida, outras (sic) são adquiridas pelo esforço e pela ação pessoal. Este aspecto é essencialmente social e de inteligência pública. Os papéis de cada personagem que a personalidade representa são arbitrados pela sociedade. [...] A personagem é o fator que refere a pessoa a determinado público (SIMÕES, 1995, p. 62).

Simões acredita, assim, que são as pessoas, dotadas de personalidades e que exercem diferentes personagens, são as responsáveis pela construção de relacionamento e vínculos entre organização e públicos. A partir disso, pode-se dizer que é a mistura entre aspectos da personalidade dos indivíduos e aspectos dos personagens por eles exercidos que segmentam os grupos de interesses. Tais grupos constroem, então, suas respectivas intenções, objetivos e necessidades.

A perspectiva de Simões sobre públicos de interesse e relações corporativas parece adotar uma perspectiva humanizada sobre a análise de públicos, voltada para o indivíduo e seus objetivos e interesses. O autor considera, além disso, as expectativas construídas entre as partes na relação organização-público, visão essa que demonstra ser bastante contemporânea e possível de ser aplicada na atualidade. Simões não apresenta, porém, um método de mapeamento de públicos a partir das relações de poder e expectativas dos indivíduos, fator que dificulta a utilização de sua abordagem dentro das organizações, por mais contemporânea 
que ela pareça ser.

\section{CLASSIFICAÇÃO BASEADA NO RELACIONAMENTO ECONÔMICO}

Kotler (1994, p. 43) classifica os públicos de interesse de uma organização de acordo com o relacionamento econômico, ou seja, com o nível de contribuição de cada público para o sucesso financeiro da instituição. Para estabelecer essa interpretação sobre públicos, o autor leva em consideração, primeiro, os grupos que têm interesse real ou potencial na entidade, além do quanto e de que forma determinado grupo pode afetar a atuação de organização.

A visão de Kotler sobre públicos de interesse é relevante para o presente trabalho, já que o autor leva em consideração a participação de cada grupo no alcance de objetivos de negócio da instituição, para, então, estabelecer os critérios para a definição de públicos de interesse, de acordo com seu nível de relevância junto à organização.

\section{PERSONAS: CONCEITO E SUAS APLICAÇÕES}

Estudos e reportagens recentes afirmam que conhecer o cliente em profundidade para trabalhar a elaboração de estratégias de comunicação e relacionamento está na lista das tendências de comunicação e marketing da atualidade. Essa abordagem pode ser facilmente direcionada também a outros públicos de uma organização qualquer. Nesse sentido, pode-se dizer que a compreensão das necessidades, dificuldades e interesses do indivíduo precisa embasar o posicionamento estratégico e objetivos de negócio de uma organização, para que seja possível estabelecer relação de confiança com qualquer um de seus públicos. É por isso que a atividade de relações públicas precisa compreender o contexto comunicacional atual, além de aprofundar seu conhecimento quanto ao comportamento desses públicos e, assim, ser capaz de propor estratégias de comunicação que entreguem resultados.

Comunicar de forma direcionada é princípio primordial no desenvolvimento da comunicação estratégica de resultados, princípio esse que se tornou uma exigência para os setores de comunicação e marketing das organizações, que buscam formas cada vez mais eficazes de conhecer o público consumidor. Neste cenário, o conceito de personas é apropriado e adaptado por metodologias das ciências aplicadas e é utilizado para obter conhecimento sobre o público consumidor e, dessa forma, desenhar estratégias mercadológicas para alcançálo.

Assim, apresenta-se a noção de personas na perspectiva da tecnologia (focada no usuário) e do ponto de vista do marketing (focado no cliente), de forma a possibilitar o alargamento dessas compreensões, em direção a uma proposta que englobe todos os públicos de uma organização. Somente assim se pode constituir uma concepção mais apropriada à área de relações públicas, que tem início com a incorporação da noção de personas ao que se 
denomina Inbound PR.

\section{CONCEITO DE PERSONAS NA TECNOLOGIA}

Concebido como uma prática do setor tecnológico, o conceito de personas desestabilizou os complexos processos de desenvolvimento de softwares e colocou o usuário no centro das prioridades, uma prática nada comum para os desenvolvedores de sistemas da década de 1990, mas que foi proposta e explorada com êxito por Alan Cooper.

O conceito de personas foi proposto com o intuito de aprimorar o user experience design, ou design de experiência, no desenvolvimento de softwares. Personas são, de acordo com Cooper (2004), personagens fictícios que carregam objetivos, necessidades e padrões de comportamento de um usuário real ou potencial de determinado sistema. Apesar de fictícias, as personas são definidas com bastante rigor e precisão, com base em dados obtidos através de investigação e pesquisa. O autor destaca, além disso, que a definição de personas deve partir dos seus objetivos, aproximando-se da perspectiva das relações públicas sobre públicos estratégicos, que são mapeados a partir de seus respectivos interesses com relação a uma organização.

Cooper (2004) ressalta que a persona é sempre específica, com necessidades e objetivos também específicos, e rejeita a ideia de que, para ter sucesso com o desenvolvimento de uma solução, é necessário torná-la o mais genérica possível. O sucesso está, assim, na solução desenvolvida especificamente para uma pessoa com um problema específico, já que, de acordo com o autor, não existe "elasticidade" no usuário, ou seja, o usuário de um sistema não adapta suas necessidades ao sistema, mas o sistema deve adaptar-se às necessidades do usuário.

Definir uma persona envolve pesquisa recorrente e constante construção de personagens que representam possíveis usuários para, então, definir se tais personagens são de fato arquétipos, ou seja, representam as necessidades do usuário real de determinada solução tecnológica. Cooper (2004) conta que, a partir de entrevistas com representantes de possíveis grupos de usuários, são criados, normalmente, entre três e doze personas diferentes para cada projeto. O autor ressalta, também, que o sistema não é desenvolvido para todas as personas, mas que elas se tornam úteis para articular as necessidades da população de usuários. Algumas personas são, inclusive, projetadas apenas para deixar claro que o sistema não está sendo desenvolvido para elas.

Cooper (2014) segmenta personas em três categorias, e cada uma delas tem suas próprias vantagens e deficiências. São elas:

- Marketing personas se concentram em informações demográficas, motivações e preocupações de compra ou preferências de compra, mensagens-chave para o consumidor e breve mapeamento de seus hábitos de mídia. Elas são 
tipicamente descritas de forma genérica com foco em informações demográficas como, por exemplo: mulheres entre 30 e 45 anos de idade, que vivem nos EUA ou no Canadá. Marketing personas explicam o comportamento do cliente, mas não chegam ao porquê por trás dele. As marketing personas são boas para determinar quais tipos de clientes serão receptivos a determinados produtos ou mensagens, ou para avaliar o $\mathrm{ROI}^{6}$ potencial de um produto. Não são, no entanto, eficazes no processo de definição de um produto ou serviço o que é, como ele funcionará e como ele será usado, ou mesmo para priorizar recursos em um produto ou serviço.

- Proto-personas são utilizadas quando não há dinheiro ou tempo para criar personagens verdadeiros baseados em pesquisa - eles são baseados em pesquisa secundária e na percepção da equipe de desenvolvedores a respeito do usuário para o qual eles destinam seu projeto. De acordo com o Cooper (2014), usar uma proto-persona para dirigir as decisões de design ainda é melhor do que não fazer qualquer uso da abordagem de personas, embora o autor ressalte a importância destes personagens serem validados através de pesquisas.

- Design personas se concentram nos objetivos do usuário, no comportamento atual e nas dores e necessidades do usuário em oposição às suas preferências de compra ou de mídia e comportamento. Elas são baseadas em pesquisa de campo e pessoas reais. Design personas contam uma história e descrevem por que as pessoas se comportam de determinada forma, na tentativa de ajudar todos os envolvidos na concepção e construção de um produto ou serviço a entender, se relacionar e lembrar do usuário final ao longo de todo o processo de desenvolvimento do produto. Design personas são eficazes para comunicar os insights da pesquisa, ou seja, os aprendizados e dados obtidos, os objetivos do usuário, auxiliar na compreensão e foco em certos tipos de usuários e definir um produto ou serviço, além de evitar o surgimento do "usuário elástico" e o design auto referencial.

De acordo com Owens (2017), pesquisadora de user experience e designer na IBM, o conceito de personas no design e na tecnologia é voltado para a experiência do usuário, e tem muito a ver com a construção de empatia. Segundo ela, é necessário construir empatia entre os desenvolvedores e o usuário para o qual a equipe desenvolve uma solução, pois a compreensão das motivações, objetivos e comportamento da persona se tornam essenciais para que a equipe seja capaz de absorver rapidamente as informações e se concentrar na

\footnotetext{
${ }^{6} \mathrm{ROI}$ é a sigla para return on investment, ou "retorno sobre investimento", e mede o ganho ou perda gerado em um investimento relativo à quantia de dinheiro investido.
} 
entrega da melhor experiência para o usuário. Sob essa perspectiva, o conceito é chamado de user personas.

\section{PERSONAS E INBOUND MARKETING}

Em uma tradução literal do inglês para o português, inbound marketing significa "marketing de entrada", também conhecido como "marketing de atração". O termo foi utilizado pela primeira vez em 2005 por Brian Halligan, CEO da empresa Hubspot, referência internacional na metodologia, que traz para o cenário do marketing tradicional uma abordagem de atuação que tem como princípio atrair o interesse do público para fazer com que os potenciais clientes de uma organização encontrem-na e consumam os seus produtos, serviços ou soluções. Como se pode ver, essa perspectiva é inteiramente voltada ao público-cliente, sem incorporar os demais públicos com o quais as organizações se relacionam.

Segundo Godin (2000), com a permissão dos clientes, cada vez mais dados podem ser coletados, fazendo com que as empresas ganhem inteligência sobre o comportamento e as melhores práticas comunicacionais para se relacionarem com os seus públicos. Para a organização Hubspot, o inbound marketing tem seus esforços e estratégias focados na atração de clientes através de conteúdo relevante e útil, que agregue valor em todas as etapas da jornada de compra do cliente. O uso das técnicas de inbound marketing permite que potenciais clientes encontrem uma empresa através de canais de comunicação e conteúdo, como blogs, mecanismos de busca (Google) e redes sociais.

Ao criar conteúdo projetado para resolver os problemas e as necessidades de seus clientes ideais, a organização que utiliza a metodologia atrai indivíduos qualificados para realizar uma possível compra, e cria confiança e credibilidade para a empresa. Segundo o Hubspot (2017), inbound marketing é "a melhor maneira de transformar estranhos em clientes e promotores de uma empresa".

Ao conceituar inbound marketing, percebe-se um grande potencial de uso do seu discurso junto à área das relações públicas, já que a metodologia tem como objetivo específico construir reputação e reconhecimento de marca perante o público, trabalho esse que é central na atividade de relações públicas. Entretanto, enquanto o inbound marketing tem foco predominante no público consumidor, as relações públicas trabalham para disponibilizar elementos que possibilitem a construção da imagem da organização e disseminar a reputação positiva da empresa perante os seus públicos, através da construção de relacionamento com eles.

O pilar do inbound marketing que trabalha para atrair as pessoas certas para a organização é chamado de Marketing de Conteúdo, que consiste na produção de conteúdo de qualidade construído com base nos interesses dos públicos de uma organização integrado a técnicas de otimização desses conteúdos. Segundo artigo do Hubspot (2016), o conteúdo 
produzido para o público possui quatro objetivos bastante específicos, sendo eles: 1) atrair visitantes para os canais digitais de interação da organização; 2) converter esses visitantes em leads, ou seja, clientes em potencial, através da oferta de conteúdo relevante em troca de dados específicos do visitante, como e-mail e telefone; 3 ) transformar os leads captados em clientes e 4) encantar os clientes para que eles se tornem promotores de uma marca ou organização.

As quatro etapas acima representam, então, as fases do Inbound Marketing, metodologia que se desenvolve no meio online e que têm como objetivo principal captar contatos com potencial de consumo de determinado serviço, produto ou solução da organização e prepará-los para consumir efetivamente, através da produção de conteúdo e do desenvolvimento dos pontos de contato listados acima. O item a seguir apresenta alguns modelos utilizados na metodologia inbound para conhecer o público consumidor, a buyer persona, e identificar suas necessidades.

\section{CONSTRUÇÃO DE PERSONAS NO INBOUND MARKETING}

Já que a origem do conceito de personas é tecnológica e advém da construção de experiência do usuário para produtos e soluções tecnológicas, o conceito de personas na comunicação e no marketing é considerado um travelling concept ${ }^{7}$ por Feijó (2017). A abordagem de personas no contexto mercadológico carrega objetivos diferentes. Chamado de buyer persona no marketing, o conceito busca entender o comportamento do consumidor e suas necessidades, com o intuito de construir estratégias de comunicação e marketing para guiá-lo até a decisão de compra. De acordo com Sam Kusinitz, autor da organização Hubspot, a buyer persona, o cliente, é construída com base em dados demográficos reais e especulações a respeito de padrões de comportamento, motivações e objetivos de indivíduos.

Para que a metodologia inbound seja efetiva, é importante que sejam traçadas, em um primeiro momento, as personas de uma marca, serviço ou produto. Conhecer o consumidor ou potencial consumidor é o primeiro passo, e a construção de personas ajuda neste processo.

Segundo o Hubspot (2017), mapear a buyer persona de uma organização é fundamental para gerar conteúdo, desenvolver produtos, acompanhar resultados de vendas e tudo o que se relaciona com a aquisição e retenção de clientes. A construção de buyer personas é baseada em pesquisa de mercado, bem como em informações coletadas através da base de clientes reais de uma empresa.

O desenvolvimento de buyer personas pode ocorrer através de pesquisas, enquetes e entrevistas com o público de uma organização. Segundo artigo do Hubspot (2015), escrito por

\footnotetext{
7 O termo é utilizado pela socióloga holandesa Mieke Bal para representar conceitos que transitam entre disciplinas ou entre a sociedade e a cultura.
} 
Pamela Vaugh, o público entrevistado para dar base às personas de uma marca pode ser formado por uma mistura de clientes, potenciais clientes e aqueles contatos que estão fora do banco de dados da empresa mas que podem se identificar com o público-alvo da organização.

Importante ressaltar que a abordagem de personas é um pouco diferente da de público-alvo; no entanto, leva em consideração aspectos da personalidade, preferências, interesses e dificuldades do indivíduo. Enquanto o público-alvo utiliza, geralmente, dados demográficos para entender o consumidor de uma organização - como, por exemplo, gênero, idade, localização e função do indivíduo - para, então, inferir suas necessidades e interesses, a abordagem de personas permite o aprofundamento do conhecimento sobre o consumidor. Isso porque atinge nível bastante aprofundado de especificidade, com o intuito de melhor mapear as necessidades de um grupo de pessoas que são representadas por uma persona arquetípica. A metodologia inbound traça as etapas da construção de buyer personas a partir da proposta de um template para mapear as informações de cada persona.

\section{TEMPLATE PARA CONSTRUÇÃO DE BUYER PERSONAS}

O template para construção de buyer personas proposto pela Hubspot (2015) é composto por quatro seções distintas. A seção 1 aborda as características da persona; a seção 2 busca mapear os objetivos dessa persona e seus desafios, além de refletir sobre como a organização, produto ou serviço poderia ajudá-la a superar esses desafios; a seção 3 especifica as frequentes constatações e objeções do indivíduo a respeito de suas dificuldades e desafios e, por fim, a seção 4 instiga a criação de mensagens-chave para a abordagem desta persona, bem como a reflexão sobre como a organização pode ajudar este indivíduo que representará as necessidades de um grupo de consumidores.

\section{Seção 1: "Quem?”}

A seção 1 traz os seguintes questionamentos a respeito da persona que será construída, segundo modelo proposto pela Hubspot (2015):

- Background, ou experiência da persona: qual o seu emprego? Que opções de carreira essa pessoa fez? Como é o seu núcleo familiar?

- Dados demográficos: qual o gênero dessa persona? Qual a sua idade? Qual a sua renda? Onde ela mora?

- Comportamento: como se caracteriza o comportamento geral dessa persona? Quais são as suas preferências comunicacionais ou de consumo de conteúdo?

\section{Seção 2: "O quê?"}

A seção 2 aborda os objetivos primários e secundários do indivíduo, assim como seus desafios e como a empresa pode ajudá-lo a superá-los em perguntas específicas (HUBSPOT, 
2015):

- Objetivos: qual o principal objetivo desta persona? Quais são os objetivos secundários específicos?

- Desafios: qual o principal desafio da persona? Ela tem mais de um?

- O que a organização pode fazer para: 1. ajudar a persona a alcançar seus objetivos, e 2 . ajudar a persona a superar seus desafios?

\section{Seção 3: "Por quê?”}

A seção 3 exige reflexão a respeito das objeções da persona a respeito de seus desafios, com as seguintes questões (HUBSPOT, 2015):

- Citações reais da persona a respeito de seus objetivos e desafios.

- Objeções frequentes dessa persona: porque essa persona não compraria o serviço/produto/soluções da empresa?

\section{Seção 4: "Como?"}

Por último, a seção 4 pede um exercício de como as objeções dessa persona seriam descartadas, apresentando as mensagens-chaves e argumento de vendas da organização, com as seguintes questões propostas pela Hubspot (2015):

- Como descrever a solução da organização para essa persona?

- Qual o seu discurso de vendas?

Existem diversos modelos para o desenho de personas, com variações de perguntas e formatos, mas todos têm o mesmo propósito: estabelecer um olhar mais humano sobre o consumidor, com maior foco em suas necessidades do que a abordagem "alvo" de vendas oferece. Também há um website específico para a criação de personas para negócios, desenvolvido através da parceria entre as empresas Resultados Digitais e Rock Content. O Fantástico Gerador de Personas guia o visitante através de perguntas que seguem uma ordem específica e, ao final do questionário, entregam um modelo de persona construído com base nas respostas do questionário, que pode ser extraído do site em formato PDF.

A criação de um método ágil como abordagem mercadológica de personas para compreender o público consumidor pode ser importante para as organizações, visto que pode auxiliar na conexão da organização com o seu consumidor de forma mais humana e com foco nas necessidades do indivíduo que, consequentemente, resulta em vendas e alcance de objetivos monetários para a organização. A construção de um framework, com perguntaschaves sobre o indivíduo, agiliza o processo de mapeamento, simplificando-o para a equipe de 
marketing de uma empresa, pois, mesmo que a persona seja um arquétipo hipotético, ela é construída com base em informações reais sobre o consumidor - que devem, obviamente, ser validadas pela organização por meio de pesquisa, acompanhamento do comportamento do indivíduo nos canais digitais da empresa e dados obtidos sobre ele.

É possível inferir que a abordagem de personas pode ter potencial de adaptação sob o olhar das relações públicas, abrangendo os demais segmentos de públicos de uma organização e colocando sobre eles uma análise mais aprofundada e humana. Tal constatação surge a partir da compreensão de que o estudo de públicos é objeto das relações públicas (FRANÇA, 2012) e de que o mapeamento de públicos de interesse em relações públicas envolve a compreensão de expectativas dos indivíduos que compõem os diferentes públicos de uma organização (SIMÕES, 1995).

\section{PERSONAS E INBOUND PR}

Há mais aspectos em comum entre a atividade de relações públicas e a metodologia inbound. Para Feijó (2017, paginação não indicada no artigo), "muitas das técnicas descritas em inbound marketing sempre foram práticas de Relações Públicas". Segundo ela, a criação de relacionamentos de qualidade que geram resultados tanto para a empresa quanto para o indivíduo, a comunicação constante com os públicos de uma organização, a interação com o público através das mídias digitais e a construção de relacionamento com a imprensa caracterizam atividades do profissional de relações públicas e estão sendo incorporadas pela metodologia inbound. Nesse sentido, pode-se dizer que a atuação das relações públicas se ajusta perfeitamente às necessidades trazidas pelo avanço das tecnologias nas mídias digitais.

Gini Dietrich, relações públicas americana fundadora do blog SpinSucks, reconhecido mundialmente, afirma que os profissionais de relações públicas, hoje, também atuam na geração de leads, na nutrição desses contatos e no suporte aos times de vendas de uma organização ao produzir conteúdo especializado que seja relevante para esses contatos. A produção de conteúdo em diferentes formatos para atrair o consumidor, aliada às ferramentas e atividades de relações públicas, tem sido uma das estratégias mais utilizadas pelos profissionais de relações públicas contemporâneos, pois alia a construção de reputação e relacionamento com os públicos a resultado de negócios.

Foi a partir da metodologia inbound marketing e inspirada no conceito de comunicação integrada que Ariane Feijó passou a desenvolver, em 2010, a metodologia Inbound PR, apresentada no Brasil somente em 2015. Em tradução livre, Inbound PR significa relações públicas de atração e tem como principal premissa a conexão de objetivos de negócio com relações públicas, marketing e vendas. De acordo com Feijó (2017), a novidade trazida pelo Inbound $P R$ não são os processos em si, mas sim "a forma como eles estão sincronizados para gerar reputação e vendas simultaneamente". 
O método tem base em três objetivos principais: dar mais visibilidade às empresas, construir relacionamentos através da repercussão das ações de comunicação da organização com suas personas e gerar vendas e reputação simultaneamente. A irresignação da autora sobre a inaplicabilidade plena do conceito de comunicação integrada nas organizações foi o combustível para a criação do método, que surgiu a partir da ideia de sincronizar os interesses dos times de marketing e vendas das organizações com a construção de reputação da empresa através do trabalho de relações públicas.

O termo sincronizar ganha importância para o desenvolvimento do Inbound $P R$, já que, a partir do contexto tecnológico atual, pressupõe a ideia de combinar conhecimentos de organismos diferentes, que atuam de formas distintas entre si, para trabalharem de forma unificada para um mesmo propósito. Importante informar que, apesar de a estratégia de inbound ter maior concentração no meio online, a proposta inclui a utilização de ações offline de forma convergente, em que as iniciativas de um meio são estendidas para o outro com o intuito de amplificar as ações de comunicação.

Inbound $P R$ pode ser compreendido como uma nova interpretação para a comunicação integrada, revitalizando-a como comunicação sincronizada. O trabalho de Inbound $P R$ inicia em um momento anterior ao previsto pelas práticas do inbound marketing, pois olha primeiro para a organização, com a ideia de compreender seu propósito, identificar as necessidades das pessoas, ou públicos, impactadas pelo propósito da organização, e do método como se desenvolve a comunicação para esses públicos. Propósito, pessoas e método caracterizam os três pilares, ou princípios, do Inbound $P R$, pilares esses que são divididos em etapas de implementação específicas.

É possível identificar através da metodologia Inbound $P R$ o potencial de influência das relações públicas na construção de uma comunicação de resultados que seja voltada para o indivíduo, para as personas. A partir dos objetivos de negócio, definem-se as mensagens que a empresa deseja transmitir para os seus públicos. As mensagens, então, se conectam ao comportamento das personas e, dessa forma, dão base ao relacionamento construído entre as partes.

\section{CONSIDERAÇÕES FINAIS}

Fica claro como ainda há espaço para desenvolver formas mais ágeis, aprofundadas e eficazes para mapear os públicos de uma organização e estabelecer o fluxo de interações com estes públicos, que abrangem indivíduos que pertencem a outros grupos, além do consumidor. Nesse sentido, ao analisar a importância que a estratégia de comunicação para a construção de reputação vem recebendo por parte das empresas, é possível perceber uma oportunidade para a área das relações públicas. 
Ao considerar a revitalização de suas abordagens a respeito de mapeamento de públicos de interesse e ao utilizar o conhecimento aprofundado sobre relacionamentos estratégicos, é possível cogitar a construção de um método que seja mais prático e eficaz para as organizações mapearem seus públicos e que facilite, também, o processo de construção de relacionamento com estes públicos.

Os teóricos da área de relações públicas ainda não abordam um caminho totalmente claro para identificar as necessidades e mapear em profundidade os perfis e interesses dos diferentes públicos de uma organização, especialmente quando se consideram os relacionamentos construídos em ambientes digitais.

As conceituações de públicos construídas pelos pesquisadores da área das relações públicas, embora sejam bastante extensas, acabam por não entregar um formato, modelo ou caminho específico para identificar as características dos públicos com os quais a organização se relaciona e atrelar tais características à estratégia de comunicação. É possível dizer que a extensão e a complexidade das conceituações de públicos existentes dificultam sua aplicação no cotidiano das organizações, fator esse que instiga a proposição de novas concepções, mais voltadas para a esfera mercadológica.

\section{REFERÊNCIAS}

COOPER, Alan. The inmates are running the asylum. Sams Publishing, 2004.

FEIJÓ, Ariane Sefrin. INBOUND PR: A Comunicação Sincronizada que pode gerar reputação e vendas simultaneamente. Belo Horizonte: IX Congresso Abrapcorp, 2017.

FEIJÓ, Ariane Sefrin. Canvas da Comunicação. Otimifica, 2016. Disponível em: <http://otimifica.rds.land/canvas-da-comunicacao> Acesso em 17 out. 2017.

FORTES, Waldyr Gutierrez. Relações públicas: processo, funções, tecnologia e estratégias. 2a edição. São Paulo: Summus, 2003.

FRANÇA, Fábio. Gestão de Relacionamentos Corporativos. In: GRUNIG, James E.; FERRARI, Maria Aparecida; FRANÇA, Fábio. Relações Públicas Teoria, Contexto e Relacionamentos. São Paulo: Difusora, 2011.

FRANÇA, Fábio. Públicos: como identificá-los em nova visão estratégica: business relationship. 3a ed. - São Caetano do Sul, SP: Yendis Editora, 2012.

GODIN, Seth. Marketing de permissão: transformando desconhecidos em amigos e amigos em clientes. Rio de Janeiro: Campus, 2000.

GRUNIG, James E.; FERRARI, Maria Aparecida; FRANÇA, Fábio. Relações Públicas Teoria, Contexto e Relacionamentos. São Paulo: Difusora, 2011. 
GRUNIG, James E. e HUNT, Todd T. Managing Public Relations. Maryland: HBJ, 1984.

HOTMART. Como criar uma persona para o seu negócio? 2017. Disponível em:

$<$ https://blog.hotmart.com/pt-br/afiliados/como-criar-persona-negocio/> Acesso em 15 out. 2017.

HUBSPOT. Disponível em: <https://br.hubspot.com/> Acesso em: 08 set. 2017.

HUBSPOT. 0 que é Inbound Marketing? 2016. Disponível em: <https://br.hubspot.com/blog/o-que-e-inbound-marketing> Acesso em 09 set. 2017.

HUBSPOT. What is Inbound Marketing?. 2017. Disponível em: <https://www.hubspot.com/inbound-marketing> Acesso em: 09 set. 2017.

KOTLER, P.; FOX, Karen F. A. Marketing Estratégico para Instituições Educacionais. São Paulo: Atlas, 1994.

LAKATOS, Eva Maria; MARCONI, Marina de Andrade. Fundamentos de metodologia científica. 5a ed. São Paulo: Atlas, 2003.

OWENS, Stefanie. Design Personas vs Marketing Personas: They. Are. Different! Disponível em: <https://medium.theuxblog.com/design-personas-vs-marketing-personas-they-aredifferent-27 24992acc78> Acesso em: 20 jul. 2017.

PENTEADO, J.R. Whitaker. Relações Públicas nas empresas modernas. 3a edição. São Paulo: Pioneira, 1984.

SIMÕES, Roberto Porto. Relações públicas: função política. 3ạ ed. São Paulo: Summus, 1995.

STEYN, Benita. From strategy to corporate communication strategy: A conceptualisation. In: Journal of Communication Management, Vol. 8. 2 ed. Cape Town: Emerald Group Publishing Limited, 2004. 